\title{
Beyond aboveground
}

\author{
Larissa Sayuri M. Sugai ${ }^{1}$. \\ Jose M. Ochoa-Quintero ${ }^{1,2}$. \\ Raul Costa-Pereira ${ }^{3} \cdot$ Fabio O. Roque ${ }^{1}$
}

Received: 25 February 2015/Accepted: 28 March 2015/Published online: 1 April 2015

(C) Springer Science+Business Media Dordrecht 2015

Despite Brazil's role as a global environmental leader, most of its megadiverse and unique biomes are at risk (Ferreira et al. 2014). Currently, the Brazilian Congress is debating political proposals (e.g. PL 3682/2012) for the expansion of mining and hydropower generation activities across the country, including areas within the system of Brazil's protected areas. Ferreira et al. (2014) showed a detrimental perspective for the integrity of Brazil's biomes in a scenario where the ongoing proposals are approved. Areas of mining interest overlap $20 \%$ of Brazil's protected areas and indigenous lands, threatening the coverage integrity of the largest system of protected areas worldwide. Although there are compelling arguments, the authors argue that Brazil's newly elected government should maintain a consistent stance with its influential role as a leader in the conservation of natural areas by expanding the protected areas system and reducing deforestation.

Although we fully agree with the concerns of Ferreira et al. (2014), the emergent debate considers exclusively aboveground consequences of mining within Brazil's protected areas, whereas the most pervasive and direct threat of expanding mining activities is the loss of subterranean habitats, including its biodiversity and provided ecosystem services (Langer 2001).

Communicated by David Hawksworth.

Electronic supplementary material The online version of this article (doi:10.1007/s10531-015-0918-4) contains supplementary material, which is available to authorized users.

Larissa Sayuri M. Sugai

lariagus@gmail.com

1 Centro de Ciências Biológicas e da Saúde, Universidade Federal de Mato Grosso do Sul,

Campo Grande, MS 79070-900, Brazil

2 Conservation Science Group, University of Cambridge, Cambridge, UK

3 Departamento de Ecologia, Universidade Estadual Paulista 'Julio de Mesquita Filho', Rio Claro, São Paulo, Brazil 
Habitat loss due to quarrying activities, consequences of land use conversion as sedimentation, impacts on the flux of groundwater drainage, pollution, and invasive species may cause long term degradation of caves (Trajano 2000; Auler and Piló 2015). Whether these mining legislations are approved, an even more dramatic scenario than the one predicted by Ferreira et al. (2014) will threaten not only the aboveground ecosystems, but more so the integrity of Brazil's belowground ecosystems.

Following the same approach used by Ferreira et al. (2014) for Brazil's biomes, we analyzed the overlap among registered caves, mining interest areas and strictly protected areas in Brazil (see Online Resource). We found that only $11.6 \%$ from the 13,816 registered caves are within strictly protected areas (Fig. 1a), whereas $75.6 \%$ are in areas of mining interest (Fig. 1b). Also, for the two main categories of mining permission, we found that $48.9 \%$ of Brazil's caves are within areas under consideration, and $26.7 \%$ are within approved areas for mining exploitation. Alarmingly, if the Congress approves current proposals for mining expansion, almost half of the caves within protected areas are at risk to be affected (Fig. 1c). From the 1611 caves within strictly protected areas, $34.8 \%$ are in areas under consideration and $12.1 \%$ are within approved areas. Thus, only $6 \%$ of all Brazilian caves are indeed protected within strictly protected areas and out of any mining interest areas. This threatening degree of protection of Brazil's caves, together with

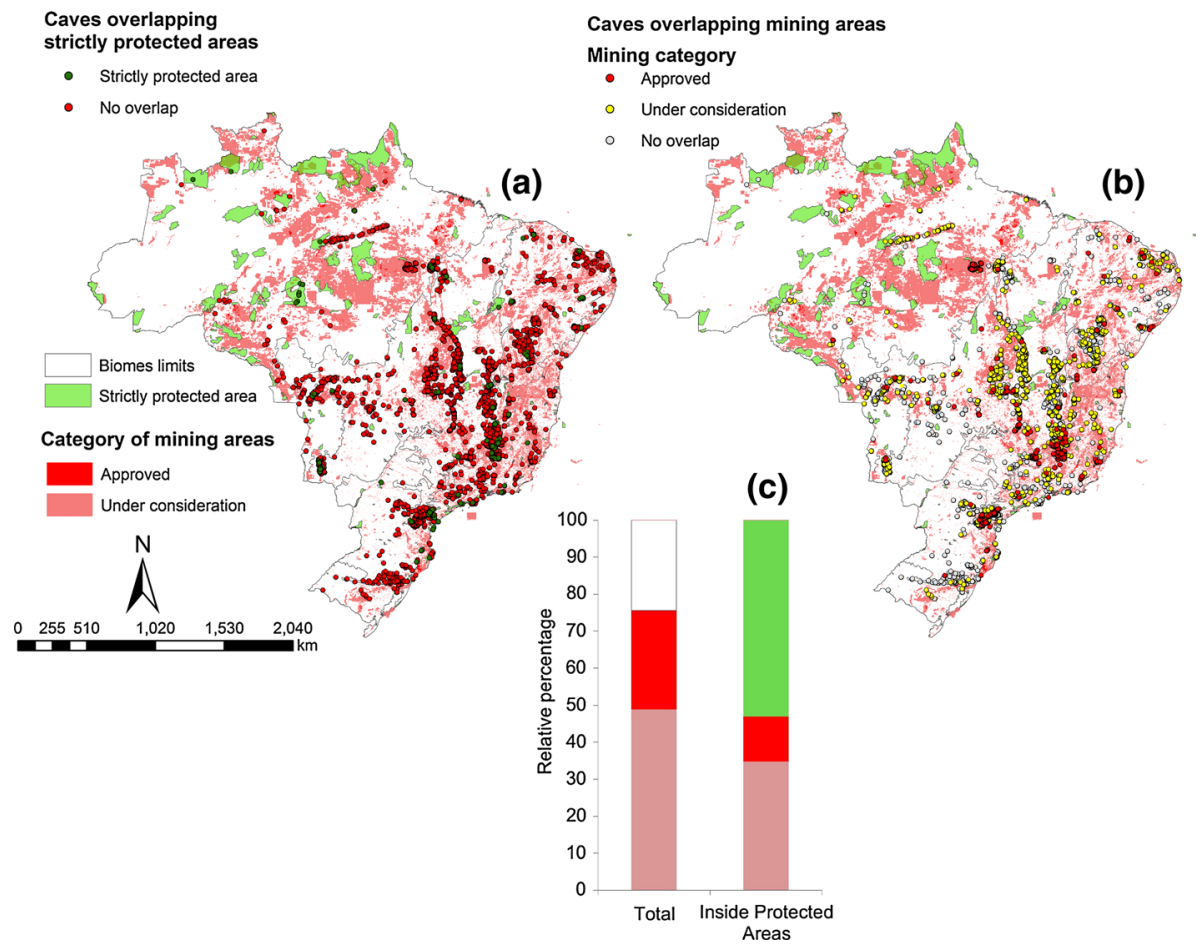

Fig. 1 The distribution of Brazil's caves and the overlapping occurrence in strictly protected areas (green) (a), and mining areas, including those with registered interest in mining activities, (under consideration, pink) and those officially approved for mining (approved, red) (b) sensu Ferreira et al. (2014). Relative percentage of total caves (total) and total caves inside protected areas (inside protected areas) in areas with registered interest in mining activities (White outside mining interest, Red approved, Pink under consideration, Green inside protected areas and out of mining interest areas) (c). (Color figure online) 
the scenario discussed by Ferreira et al. (2014), escalates the risks that Brazil's biomes as a whole are facing.

An important legal mechanism for cave conservation is the Normative Resolution $347 / 2004$ (see Online Resource for information about these legislation), updated by the Federal Decree 6.640/2008 and Normative Instruction 2/2009, which resolves the creation of relevance classes for caves. During licensing of mining concessions, if a cave is classified as "maximum relevance", its exploitation is not allowed. But the protection of the underground biodiversity involves more than safeguarding individual caves. The large spatial extent of the potential impacts of mining across the country (Fig. 1) leads Brazil's cave network and the surrounding landscape to serious threats. Thus, direct (e.g. structural damages, sedimentation) and indirect pressures (e.g. surrounding cave's landscape coverage change) of mining can predispose the cave systems to similar collapses as those identified by Laurance et al. (2012) for tropical forests.

Most inferences on ecosystem and landscape integrity are based on vegetation and landuse cover assessments, for which monitoring systems, based on remote sensing technologies, are widely spread (Turner et al. 2003). However, these approaches mostly capture aboveground changes, while the remote assessment of anthropogenic impacts on subterranean ecosystems are difficult to map and monitor, especially on a large scale. For Brazil's caves, data about degradation, current situation, and threats are being compiled by the National Cave Database. But the overall process is time-consuming, because minimum conclusions to determine the importance of a given cave require up to 1.5 years to be achieved (Auler and Piló 2015). In addition, the tools used to reduce or revert anthropic threats (i.e. offsetting and restoration) are designed for aboveground changes like deforestation (Ferreira et al. 2014; Soares-Filho et al. 2014), and despite being an existing legal mechanism for caves (Normative Instruction 2/2009), they are undoubtedly questionable because mining impacts on caves, and their associated environments, are usually irreversible.

This scenario sets Brazil's subterranean environments as a highly threatened system, disarmed of a consistent debate in face of the recent environmental pressures. For these unique systems, that harbor high levels of endemism and provide essential ecosystem services (e.g. water supply), the network of Brazil's protected areas does not warrant a safe degree of protection, and pressures derived from mining activities expansion can irreversibly affect the integrity of the underground environment.

The newly elected government has the opportunity to refuse short-lived and environmentally impactful development projects in order to maintain Brazil's role as an environmental leader. In addition to the compelling evidence of Ferreira et al. (2014), we include the alarming impacts on the subterranean environments if mining exploitation is allowed in protected areas. We argue that current political debate should go beyond deforestation and forest degradation, and include the integrity of subterranean ecosystems, improving both above and belowground comprehensiveness of Brazil's biodiversity protection system.

Acknowledgments RCP is grateful to Fundação de Amparo à Pesquisa do Estado de São Paulo for the Phd grant (process \#2014/20924-5). FOR is research fellow of the Conselho Nacional de Desenvolvimento Científico e Tecnológico. JMOQ is grateful to Coordenação de Aperfeiçoamento de Pessoal de Nível Superior.

Conflict of interest The authors declare that they have no conflict of interest. 


\section{References}

Auler AS, Piló LB (2015) Caves and mining in Brazil: the dilemma of cave preservation within a mining context. In: Andreo B, Carrasco JJ, Durán F, Jiménez P, LaMoreaux JW (eds) Hydrogeological and environmental investigations in karst systems, 1st edn. Springer, Berlin, pp 487-496

Ferreira J, Aragão LEOC, Barlow J et al (2014) Brazil's environmental leadership at risk. Science 346:706-707. doi:10.1126/science.1260194

Langer WH (2001) Potential environmental impacts of quarrying stone in karst-a literature review. U.S. Geological Survey. http://geology.cr.usgs.gov/pub/ofrs/OFR-01-0484/. Accessed 10 Dec 2014

Laurance WF, Useche DC, Rendeiro J et al (2012) Averting biodiversity collapse in tropical forest protected areas. Nature 489:290-294. doi:10.1038/nature 11318

Soares-Filho B, Rajão R, Macedo M et al (2014) Cracking Brazil's forest code. Science 344:363-364. doi:10.1126/science. 1246663

Trajano E (2000) Cave Faunas in the Atlantic tropical rain forest: composition, ecology and conservation. Biotropica 32:882-893. doi:10.1111/j.1744-7429.2000.tb00626.x

Turner W, Spector S, Gardiner N et al (2003) Remote sensing for biodiversity science and conservation. Trends Ecol Evol 18:306-314. doi:10.1016/S0169-5347(03)00070-3 